\title{
Ameliorative Effect of Methanol Extract of Tiger Nut (cyperus Esculentus) On Oxidative Stress Induced By Lead Poisoning In Red Sokoto Goat
}

\author{
Adam $\mathbf{M}^{1^{*}}$, Esievo K. A. N. ${ }^{2}$, Ayo J. $\mathrm{O}^{3}$., Bisalla $\mathrm{M}^{2}$ and Adamu $\mathrm{S}^{2}$ \\ ${ }^{1}$ Department of Veterinary Pathology, Faculty of Veterinary Medicine, University of Ilorin, Ilorin, Nigeria \\ ${ }^{3}$ Department of Veterinary Pathology, Faculty of Veterinary Medicine, Ahmadu Bello University Zaria, Nigeria \\ ${ }^{3}$ Department of Veterinary Physiology, Faculty of Veterinary Medicine, Ahmadu Bello University Zaria, Nigeria
}

Accepted December 2019, and Published December, 2019

\begin{abstract}
Tiger nut is a small tuberous rhizome with medicinal and antioxidant properties. The present study was conducted to investigate the ameliorative effect of the methanol extract of tiger nut against the oxidative stress induced by lead acetate poisoning in Red Sokoto goat (RSG). Twelve adults Red Sokoto goat (16.50 \pm 1.41 to $21.92 \pm 0.97 \mathrm{~kg}$ ) were grouped into four. Group I was administered with equivalent volume of distilled water. Group II was administered with lead acetate $(200 \mathrm{mg} / \mathrm{kg})$ only. Group III was administered with methanol extract of tiger nut (METN) (150 mg/kg) and lead acetate (200 mg/kg). Group IV was administered METN (200 mg/kg) only. The serum oxidative stress changes in the different experimental groups were determined by commercial kits. The distilled water group showed no toxic response. The lead acetate (200 mg/kg) group showed decreased activity levels of glutathione, superoxide dismutase (SOD) and catalase (CAT). The cotreatment groups with lead acetate and METN showed an increase in serum glutathione peroxidase (GPX) activity, CAT and SOD. Additionally, there was a decreased MDA concentration in the same group. The group administered with METN only showed slight changes in the activities of oxidative stress makers. In conclusion, Oxidative stress biomarkers such as glutathione peroxidases, superoxide dismutase, catalase and malondialdehyde were altered in a manner indicative of oxidative stress following lead acetate exposure and ameliorated to some extent by methanolic extract of tiger nut.
\end{abstract}

Keywords: Tiger nut, Red Sokoto Goat, Oxidative Stress, Lead poisoning

Corresponding Author:

email: abumaryamasabe@gmail.com

Tel.: +234 (0)803523 371 


\section{INTRODUCTION}

Tiger nut is botanically called Cyperus esculentus belongs to the family Cyperaceae. It is also known as almond or yellow nut grass. The small tuberous rhizomes can be eaten raw or roasted [1]. Three varieties; black, brown and yellow were known and cultivated in Nigeria [2]. The yellow variety is preferred to other varieties because of its size, colour and fleshier body [3]. Lead poisoning is the most common metal poisoning affecting domestic animals because of their susceptibility and indiscriminate feeding habits [4]. Lead is a metal component used in manufacturing of grease, batteries, paints, and oils for car pipes, engines, and farm machinery. It is also associated with artisanal mining practices [4]. It is a toxic metal that causes environmental hazard which has health hazard in human and animal health [5]. Lead poisoning in animals can be via oral or respiratory route. It affects the kidneys, liver, bone marrow, bone, gastrointestinal tract, blood vessels, nervous, reproductive and endocrine systems [6]. The mechanism of action of lead toxicity is to induce oxidative stress through the generation of reactive oxygen species (ROS) from detrimental tissue responses that impair metabolism and cellular structural components [7]. Although several studies on the adverse effects of lead poisoning have been carried out on different animal species, the present study was aimed at the ameliorative effect of the methanol extract of Tiger nut (METN) considering its antioxidant composition and properties on oxidative stress induced by lead poisoning in Red Sokoto goat (RSG).

\section{MATERIALSAND METHODS}

Experimental Animals and Housing: Twelve adults male RSG within the age range of 6 months to one year weighing $16.50 \pm 1.41$ to $21.92 \pm 0.97 \mathrm{~kg}$ were procured from Maiadua goat market in Katsina State, Nigeria. The animals were kept in the animal house of the Department of Veterinary Physiology, Ahmadu Bello University, Zaria. They were fed with grass, hay, wheat bran, groundnut haulms at intervals during the early hours of the day and supplemented with $2 \mathrm{~kg}$ of concentrate feeds later in the day, and were given access to water ad libitum. The blood animals on arrival were weighed using weighing balance. The blood and faecal samples were taken for parasites.

Chemical: Lead (II) acetate was procured from Sigma Chemical Co., USA (Bristol ScientificSigma-Aldrich, Germany). Lead (II) acetate (LA) and methanol extract of tiger nut (METN) at a dose of $200 \mathrm{mg} / \mathrm{kg}$ and $150 \mathrm{mg} / \mathrm{kg}$ was dissolved in equivalent volume of distilled water (DW) respectively and prepared for the relevant groups prior to its daily administration.

Experimental Protocol: The median lethal dose $\left(\mathrm{LD}_{50}\right)$ of lead acetate and the methanol extract of tiger nut was determined using wistar rat as described by [8]. Dosage of lead acetate and tiger nut was determined using $1 / 10^{\text {th }}$ of $4000 \mathrm{mg} / \mathrm{kg}$ lead acetate and $1500 \mathrm{mg} / \mathrm{kg}$ methanol extract of tiger nut. The actual dose was calculated as ratio of dosage per body weight and concentration. Twelve adults Red Sokoto goats were randomly divided into four groups (I, II, III and IV), with three goats in each group. Group I was administered equivalent volume of distilled water. Group II were administered lead acetate $(200 \mathrm{mg} / \mathrm{kg})$ only. Group III were administered methanol extract of tiger nut $(150 \mathrm{mg} / \mathrm{kg})$ and lead acetate $(200 \mathrm{mg} / \mathrm{kg}$ ). Group IV received methanol extract of tiger nut $(200 \mathrm{mg} / \mathrm{kg})$ only. The different regimens were administered per os once daily using $20 \mathrm{ml}$ syringe for a period of twenty weeks. During the course of the experiment and after the end of the study goats 
in each group were subjected to post mortem for gross examination.

Ethical approval for the use of Red Sokoto goat for this study was obtained from the Ahmadu Bello University Committee on Animal Use and Care, Ahmadu Bello University, Zaria, Nigeria. Two milliliters of blood was collected every two days into serum sample bottle through jugular venepuncture for the period of the study. The collected blood was allowed to clot and centrifuged at $1000 \times \mathrm{g}$ for 10 minutes using micro-centrifuge $5418 \mathrm{R}$ (Eppendorf, Ontario, Canada), to obtain serum for analyses.

\section{Oxidative Stress Assays:}

Glutathione peroxidase (GPx) activity was measured according to [1]. $250 \mu \mathrm{L}$ serum was added to reaction mixtures containing $250 \mu \mathrm{L}$ $0.1 \mathrm{M}$ phosphate buffer $(\mathrm{pH}, 7.4), 50 \mu \mathrm{LNaNO}_{3}$, $\mathrm{GSH}, 100 \mu \mathrm{L} \mathrm{H}_{2} \mathrm{O}_{2}$, and $300 \mu \mathrm{L}$ of distilled water. The mixture was incubated at $37^{\circ} \mathrm{C}$ for 5 minutes. $250 \mu \mathrm{L}$ of tri-carboxylic acid was then added to the mixture and centrifuged at $1000 \mathrm{xg}$ for 10 minutes. $100 \mu \mathrm{L}_{\text {of }} \mathrm{K}_{2} \mathrm{HPO}_{4}$ and di-t-butyl nitroxide was added to $50 \mu \mathrm{L}$ of resulting supernatant aliquoted into 96-well microtiter plates. The absorbance was then read at $405 \mathrm{~nm}$ against distilled water blank using a spectrophotometer.

Superoxide dismutase (SOD) level in serum samples was determined as described by [9] and [10]. $20 \mu \mathrm{L}$ of serum was added to $250 \mu \mathrm{L}$ of $0.05 \mathrm{M}$ carbonate buffer ( $\mathrm{pH}$ 10.2). $300 \mu \mathrm{L}$ of acidified reconstituted adrenaline was then added to the ensuring mixture after which the change in absorbance was observed for 3 minutes at $490 \mathrm{~nm}$ wavelength.
Malonaldehyde (MDA) activity was evaluated using method described by [11]. $400 \mu \mathrm{L}$ of Tris$\mathrm{KCl}, 125 \mu \mathrm{L}$ of $30 \%$ tri-carboxylic acid, $100 \mu \mathrm{L}$ of serum, and $125 \mu \mathrm{L}$ of $0.75 \%$ thiobarbituric acid prepared in $0.2 \mathrm{M} \mathrm{HCl}$. The plate was incubated for 45 minutes at $80^{\circ} \mathrm{C}$ in a water bath, cooled on ice and centrifuged for 15 minutes at $1000 \mathrm{x}$ g. The absorbance was further read at $490 \mathrm{~nm}$ against distilled water as blank. Lipid peroxidation level (units/milligram protein) was evaluated on a molar extinction coefficient of $1.56 \times 10^{5} / \mathrm{M} / \mathrm{cm}$.

For the measurement of catalase (CAT) activity, the enzyme samples were prepared according to the method of [12]. Ethanol (1.0\%, vol/vol) and Triton X-100 (1.0\%, vol/vol) were added to the homogenate to stabilize and to release, respectively, the membrane bound CAT. Catalase activity was determined by following the disappearance of $\mathrm{H}_{2} \mathrm{O}_{2}$. Absorbance at 240 $\mathrm{nm}$ was recorded for 1 minute at $25^{\circ} \mathrm{C}$. One unit of CAT is defined as half of the peroxide oxygen liberated from the $\mathrm{H}_{2} \mathrm{O}_{2}$ solution in $100 \mathrm{sec}$ at 25 ${ }^{\circ} \mathrm{C}$.

\section{Data Analyses}

Values obtained were expressed as mean \pm SEM and subjected to statistical analysis using oneway analysis of variance (ANOVA), followed by Tukey's post-hoc multiple comparison test. GraphPad prism version 5.0 (San Diego, California, USA) was used for the analyses. Values of $\mathrm{P}<0.05$ were considered significant. 
Table 1: Phytochemical composition in methanol extract of tiger nut (Cyperus esculentus)

\begin{tabular}{lll}
\hline Phytochemicals & Composition $(\mathrm{mg})$ & Percentage composition (\%) \\
\hline Alkaloids & 0.820 & 61.0 \\
Phenols & 0.127 & 9.5 \\
Tannins & 0.039 & 2.8 \\
Flavonoids & 0.005 & 0.3 \\
Saponins & 0.213 & 15.8 \\
Steroids & 0.039 & 2.8 \\
Glycosides & 0.100 & 7.8 \\
\hline
\end{tabular}

Table 2: Micro-elements composition in methanol extract of tiger nut (Cyperus esculentus).

\begin{tabular}{ll}
\hline Elements & Composition $(\mathrm{mg} / \mathrm{kg})$ \\
\hline $\mathrm{Fe}$ & 190.3 \\
$\mathrm{Zn}$ & 48.5 \\
$\mathrm{Cu}$ & 7.10 \\
$\mathrm{Mn}$ & 26.5 \\
$\mathrm{Se}$ & 0.54 \\
\hline
\end{tabular}

Table 3: Influence of methanol extract of tiger nut on serum glutathione peroxidase (GP $\mathrm{x}$ ), superoxide dismu tase (SOD), catalase (CAT) and malondialdehyde (MDA) activity in Red Sokoto goats treated with lead acetate at $200 \mathrm{mg} / \mathrm{kg}$ for 20 weeks.

\begin{tabular}{lllll} 
Parameters & DW & LA & LA + METN & METN \\
\hline GPx & $81.00 \pm 0.577^{\mathrm{a}}$ & $30.00 \pm 2.887^{\mathrm{b}}$ & $63.33 \pm 1.667^{\mathrm{ba}}$ & $75.00 \pm 2.887^{\mathrm{ab}}$ \\
SOD & $0.733 \pm 0.033^{\mathrm{a}}$ & $0.300 \pm 0.057^{\mathrm{b}}$ & $0.600 \pm 0.057^{\mathrm{a}}$ & $0.800 \pm 0.057^{\mathrm{ba}}$ \\
CAT & $10.50 \pm 0.289^{\mathrm{a}}$ & $5.167 \pm 0.441^{\mathrm{b}}$ & $8.167 \pm 0.441^{\mathrm{ba}}$ & $10.33 \pm 0.601^{\mathrm{b}}$ \\
MDA & $4.000 \pm 0.577^{\mathrm{a}}$ & $11.33 \pm 0.441^{\mathrm{b}}$ & $4.667 \pm 0.882^{\mathrm{a}}$ & $4.333 \pm 0.333^{\mathrm{a}}$ \\
\hline
\end{tabular}

$\mathrm{a}, \mathrm{b}, \mathrm{c}=$ Values of mean $\pm \mathrm{SEM}$, in the same row with different superscripts are significantly different $(\mathrm{p}<0.001)$.

\section{RESULT AND DISCUSSION}

The result of the phytochemical analysis of the methanol extract of tiger nut are as presented in Table 1 while the percentage evaluation of micro - mineral elements of tiger nuts are shown in Table 2. Alkaloids (61\%) had the highest percentage, followed by saponins $(15.8 \%)$, phenols $(9.5 \%)$, glycosides $(7.8 \%)$, tannins and steroids $(2.8 \%)$, with flavonoids having the least value, $(0.3 \%)$. The microelement with highest value is iron (190.3 $\mathrm{mg} / \mathrm{kg})$ with selenium $(0.54 \mathrm{mg} / \mathrm{kg})$ as the lowest as shown in Table 2. As shown in Table 3 , there was a significant increase $(\mathrm{P}<0.001)$ in serum glutathione peroxidase activity when LA $(30.00 \pm 2.887)$ was compared to LA + METN (63.33 \pm 1.667$)$ in GPx group. There was also a significant increase $(\mathrm{P}<0.001)$ in superoxide dismutase activity when LA (0.300 
$\pm 0.057)$ was compared to LA $+\operatorname{METN}(0.600 \pm$ $0.057)$ in SOD group. Again, there was a significant increase $(\mathrm{P}<0.001)$ in catalase activity when LA $(5.167 \pm 0.441)$ was compared to LA + METN $(8.167 \pm 0.441)$ in CAT group. In the MDA group there was a significant decrease $(\mathrm{P}<0.001)$ in the malondialdehyde concentration when LA $(11.33 \pm 0.441)$ was compared to $\mathrm{LA}+\operatorname{METN}(4.667 \pm 0.882)$.

The present study showed the presence of phytochemicals and mineral elements in tiger nut such as flavonoids, phenols, zinc and selenium which have been reported to have antioxidant properties [13]. Therefore the presence of these phytochemicals in the methanol extract of tiger nut might have contributed to its antioxidant role in the lead acetate combined with methanol extract of tiger nut treated group. The present showed a significant decrease in LA treated groups. The low activity of GPx in this may be attributed to increase activity over synthesis; hence exhausted supply of GPx in response to LA provoked oxidative injury. The implication of low GPx activity as recorded in the LA group is that the hydrogen peroxide and lipid peroxide are not detoxified and may be converted to $\mathrm{OH}$ radicals and lipid peroxyl radicals respectively by lead as reported by [14]. The high level of GPx activity in the LA + METN treated group signifies a balance between the antioxidant and pro-oxidant. This implies that the animals in those groups were not undergoing oxidative stress. This was similar to the report of [15].

The results of this study indicated a significant decrease catalase activity in LA treated group. Catalase is a major antioxidant enzyme with heme as the prosthetic group [16] and can convert $\mathrm{H}_{2} \mathrm{O}_{2}$ into $\mathrm{H}_{2} \mathrm{O}$ [17]. These findings corroborate the report of [18] who observed in their study a marked decrease in serum CAT activity following LA exposure in broilers. The decrease in the CAT activity in the LA treated groups may be linked to a decrease in SOD activity, which reduces the rate of conversion of $\mathrm{O}^{2-}$ to $\mathrm{H}_{2} \mathrm{O}_{2}$ the substrate for CAT. The lack of substrate for CAT activity eventually resulted in its reduced activity. Accumulation of $\mathrm{O}^{2-}$ through SOD activity inhibition has been shown to inhibit CAT activity [19], since $\mathrm{O}^{2-}$ converts feroxy state of CAT activity to ferryl state, which is an inactive form of the CAT [5]. The decrease CAT activity may also be due to persistent long-term increased lipoperoxidation induced by administration of lead acetate, which results in increased CAT utilization and decreased synthesis due to high amounts of free radicals in the biosystem [20]. The relative decrease in the serum SOD activities in the lead acetate group can also be attributed to an enhanced superoxide generation and utilization of this enzyme during the detoxification of reactive metabolites induced by the administration of lead acetate [21]. The reduction in the activity of SOD in the lead acetate-treated groups was similar to the report of [22]. The high level of SOD activity in LA + METN treated group suggests the ability of METN to inhibit and exhaust the reactive oxygen species generated by lead from the tissue. The catalytic removal of ROS by SOD is extremely important as it prevents numerous lipid peroxidation by-products, protein adduction and organ dysfunction [23]. Based on the result of the phytochemical analysis of METN, alkaloids had high amounts, which are known to effectively stimulate generation of free radicals due to its high toxic activity [24]. Among the antioxidant enzymes, SOD is always considered as the first line of defense against oxygen toxicity due to the inhibitory effects on oxy-radical formation [6]. It scavenges the superoxide anion to form oxygen and hydrogen peroxide and thus reduce the toxic injury caused by MDA [22]. Malondialdehyde is in many instances the most abundant aldehyde arising from lipid peroxidation and hence is used as an indicator of oxidative damage in tissues [23]. 
Serum and tissue MDA level is an indicator of free radical generation, which increases in condition of oxidative stress [24].

\section{Conclusion}

Oxidative stress biomarkers such as glutathione peroxidases, superoxide dismutase, catalase and malondialdehyde were altered in a manner indicative of oxidative stress following lead acetate exposure and ameliorated to some extent by methanol extract of tiger nut.

\section{REFERENCES}

1. Beutler, E., Duron, O., and Kelly, B.M. (1963). Improved method for the determination of blood glutathione. Journal of Laboratory Clinical Medicine, 61: $882-888$.

2. Oyedepo, T. A and Odoje, O. F, (2014). Hepato-protective activities of tiger nut (Cyperus esculentus) against hepatotoxicity induced by carbon tetrachloride in rats. Journal of Pharmacology and Toxicological Studies, 2(4): 37-41.

3. Adejuyitan, J.A. (2011). Tiger nut processing: its food uses and health benefits. American Journal of Food Technology, 6(3): 197-201.

4. Majiya, M.H, Abdulmumin, A.N, Sallau, M.S., Hussaini, M.M. and Mohammed, A.K. (2015). Zamfara lead poisoning saga: Comparison of lead contamination level of water samples and lead poisoning in Bagega Artisanal gold mining district, Nigeria. Journal of Chemical and Pharmaceutical Research, 7(3): 7-12.

5. Freeman, B.A. and Capo, J.D. (1982). Biology of disease, free radicals and tissue injury. Laboratory Investment, 47: $412-415$.

6. Firat, Y., Engin-Ustun, Y., Kizilay, A.,
Ustun, Y., Akarcay, M., Selimoglu, E. ( 2009). Effect of intranasal estrogen on vocal quality. Journal of Voice, 23: 716-720.

7. Bamishaiye, E.I. and Bamishaiye, O.M. (2011). Tiger nut: As a plant, its derivatives and benefits. African Journal of Food Nutrition and Development, 11:5157-5170.

8. Lorke, D. (1983). A new approach to tropical acute toxicity testing. Archives of Toxicology, 53:275-287.

9. Maier CM, Chan PH (2002). Role of superoxide dismutases in oxidative damage and neurodegenerative disorders. Neuroscientist, 8: 323-334.

10. Nazifi, S., Saeb, M., Ghafari, N., Razeghian, I., Razavi, S.M., Soughi, V.O., Dehghani, F. and Orangi, H. (2014). Reference values of oxidative stress parameters in adult native Iranian goats. Bulgarian Journal of Veterinary Medicine, 12(2): 119-124.

11. Varshney, R. and Kale, R. K. (1990). Effects of calmodulin antagonists on radiation induced lipid peroxidation in microsomes. International Journal of Radiation Biology, 58: 733-743.

12. Cohen, G., Dembiec, D., and Marcus, J. (1970). Measurement of catalase activity in tissue extracts. Analytical Biochemistry, 34: 30-38.

13. Achoribo, E. S. and Ong, M. T. (2019). Antioxidant screening and cytotoxicity effect of tiger nut (Cyperus esculentus) extracts on some selected cancer-origin cell lines. Euro Mediterranean Biomedical Journal, 14(01): 001-006.

14. Sadhana, S., Veena, S. and Ritu, P.P (2011). Lead toxicity, oxidative damage and health implications. A review. International Journal for Biotechnology and Molecular Biology Research, 2(13): 215-221. 
15. Omobowale, T.O., Oyagbemi, A.A., Oyewunmi, O.A., and Adejumobi, A. O. (2015). Chemopreventive effect of methanol extract of Azadirachta indica on experimental Trypanosoma brucei induced oxidative stress in dogs. Pharmacognosis Research, 7: $249-$ 258.

16. Tabet, N., Mantle, D., Walker, Z. and Orrell, M. (2001). Vitamins, trace elements, and antioxidant status in dementia disorders. International Psychogeriatric, 13(3): 265-275.

17. Sujatha, K.,. Karamala, S.1., Anjaneyulu, Y., Chandra, Sekhara, R. T. S., Sreeni, V. D. and Amravathi, P. P. (2011). Hematobiochemical changes of lead Poisoning and amelioration with Ocimum sanctum in wistar albino rats. Veterinary World, .4(6): 260-263.

18. Prvulović, D., Popović, M., Kojić, D and Grubor-Lajšić, G (2014). Effects of dietary lead acetate and aluminosilicates on the antioxidative defense system of broilers' muscle tissues. Iranian Journal of Veterinary Research, Shiraz University, 15(3): 223-226.

19. Khoshvaghti, A., Askari, A., Nazifi, S. and Ghane, M. (2014). Evaluation of Some Antioxidant Enzymes in Cattle Infected with Foot and Mouth Virus. Journal Faculty of Veterinary Medicine Istanbul University, 40 (1): 70-75.
20. Norma, F. S. S., Raul, S. C., Claudia, V. C. and Beatriz, H. C. (2019). Antioxidant compounds and their antioxidant mechanism. Inteopen, 8(5): 001-28.

21. Kono, Y. and Fridovich, I. (1982). Superoxide radicals inhibit catalase. Journal of Biological Chemistry, 257: 5751-5754.

22. Afolabi, O.B., Oloyede, O.I., Jaiyesimi, K.F., Obafemi, T.O., Awe, J.O. and Fadaka, A.O. (2014). Antagonistic potentials of Talinum triangulare extracts against iron II- induced oxidative stress in tissue homogenates of Wistar albino rat - in vitro. World Journal of Pharmacology and Pharmaceutical Science, 4(6): 59-67.

23. Konstantinos, M., Vasiliki, T. and Epaminondas, Z. (2017). Role of oxidative stress and mitochondrial dysfunction in sepsis and potential therapies. Oxidative Medicine and Cellular Lungevity, 5(3): 50-63.

24. James, P.K. and Lars-Oliver, K. (2015). Free radicals and related reactive species as mediators of soft tissue injury and disease: implications for health. Critical Reviews in Toxicology, 45(9): 765-798. 